\title{
ABC STRATEGY: HOW UNIVERSITY STUDENTS PERCEPTION OF ABC STRATEGY INFLUENCES UPTAKE OF REPRODUCTIVE HEALTH PROGRAMS
}

\author{
Mary Wanjau ${ }^{1}$, Lucy kathuri-Ogola ${ }^{2}$ and Lucy Maina ${ }^{3}$ \\ ${ }^{1}$ Kenyatta University and Department of Community Development, Pan Africa Christian University, Kenya \\ ${ }^{2}$ Department of Community Resource Management, Kenyatta University, Kenya \\ ${ }^{3}$ Department of sociology, Kenyatta University, Kenya
}

\begin{abstract}
:
Background: Attitude is what influences all actions an individual undertakes in life. Young adult's attitude on sexual reproductive health has proven to have a significant influence on their sexual health lifestyle and access to healthcare. Institutions of higher learning have put in place measures to ensure student have access to youth friendly services yet this has not been matched with students utilizing the various reproductive health services within the university. To fully understand students attitude towards uptake of reproductive health services, the current study grounded on the health belief model builds on previous researches examining on youth attitudes' to sexual and reproductive health. Methodology: Reflecting on 178 structured questionnaire administered to undergraduate students in Kenyatta University. Results: This paper highlights how students' attitude to ABC strategy influences uptake of reproductive health services. Results indicated that student had a negative attitude towards abstaining, nearly half had a positive attitude to being faithful to one partner. Chi square results revealed significant relationships between uptake of reproductive health services and students attitude to abstinence till marriage $(\mathrm{p}=0.014)$, attitude in condom use ( $\mathrm{p}=0.005$ Discussion: Findings also showed a positive attitude to condom use contrary to some literature on the use of condoms among youths. ABC strategy had a significant impact on uptake to reproductive health progammes. The study established that students' attitude to the ABC strategy for protective sexual behaviour influenced uptake of reproductive health services. Conclusion: In light of these findings, the study recommends need for reproductive health programmes to redouble their efforts in strengthening the $\mathrm{ABC}$ strategy among university students in order to positively influence students' sexual attitudes and behaviour.
\end{abstract}

Keywords: Attitudes, ABC, Sexual reproductive health, Students, Uptake

\section{Introduction}

High risk sexual behaviors (HRSB), include multiple sexual partners, inconsistent condoms use, sex for favors, drugs and alcohol abuse that culminate in sexually transmitted infection (STI), including Human Immunodeficiency Virus (HIV), unplanned pregnancy and abortion (Johnson, 2011). Johnson further stipulates that HRSB, are established during adolescence, and often maintained into adulthood, affecting the health and wellbeing of an individual later in life. Several studies have noted that university students' engage in high risk sexual behaviors (Sinead et al., 2013; Heeren et al., 2012; Mwangi, Ngure and Thiga, 2012; Adam and Mutungi, 2007).

High risk sexual behavior of young adults has become of serious concern for institutions of higher learning because of the adverse consequences that are linked with young adults' engagement in HRSB (Moronkola and Idris, 2013). In addition, Moronkola and Idris noted that in the last two decades, this concern has been marked by the increasing number of reproductive health interventions aimed at young adults that have been established 
in different parts of the world. Globally, there has been enormous effort to curb high risk sexual behavior among university students who are mainly young adults and form a strong pillar of every economy. As students continue to engage in HRSB it affects their health and well-being which is crucial to economic development and attainment of Sustainable Development Goals (SDG's). HRSB has been categorized as one of the health risk behaviours consistently found to correlate with increased morbidity and mortality rates among young people emanating from unplanned pregnancies, abortions, STIs, HIV and AIDS (Sinead et al., 2013, Godia, 2012, Kirby et al., 2010). The World Health Organization (2009b) reported that HRSB practises are estimated to be the second most important global health risk factor in the world, and linked to the spread of HIV (WHO 2009a). According to Schmidt (2015) HRSB also poses the possibility of both emotional distress and has costly physical health outcomes

Despite the availability of programmes aimed at curbing high risk sexual behavior, studies continue to reveal the increase in high risk sexual behavior among university student. In addition general uptake of reproductive health services by the adolescents and youths remains a worrying concern. (Sinead et al., 2013; Heeren et al.,2012; Mwangi et al., 2012; Kimiywe et al., 2008; Manoti 2015; Miller et al., 2008; Adam and Mutungi, 2007).

\section{Problem statement}

Like many public Universities, Kenyatta University (KU) has in place RH programs and services that offer preventive and curative services on STIs and HIV. These services promote safe sexual behavior among students' through counseling, HIV testing, condom distribution, seminars and workshops on reproductive health in order to curb HRSB. However, several studies continue to show that HRSB among University students is on the increase despite the availability of a variety of reproductive health programmes to curb the behavior (Evidence to Action) (E2A), 2016; Manoti, 2015; Sinead et al., 2013; Mwangi et al., 2012; Kenya National Bureau of Statistics (KNBS) and ICF Macro, 2010; Kimiywe et al., 2008; Miller et al., 2008; Adam and Mutungi, 2007). Based on available literature so far, many of the studies conducted in universities have mainly focused on uptake of HIV and AIDS programmes especially the testing for HIV and AIDS, Voluntary Counseling and Testing (VCT) programmes. Notably, little has been done to establish the extent of uptake of programmes such as the peer counseling and mentoring services established to curb HRSB among university students. Walsh et al., (2010) assert that although the implementation of such services is encouraging, creating services does not guarantee their use. Walsh et al., 2010 adds that attitude is what influences all actions an individual undertakes in life. Young adult's attitude on sexual reproductive health has proven to have a significant influence on their sexual health lifestyle and access to healthcare. As a result, the foregoing discussion provides a background that necessitated the need to undertake this study which assessed how students' attitude influenced uptake of Reproductive Health Services (RHS) in Kenyatta University.

\section{Purpose of the study}

The purpose of this study was to determine students' attitudes on ABC strategy and how it influences their uptake of reproductive health services

\section{Objectives of the study}

This study was guided by the following specific objectives: 1)To assess influence of students' attitude towards abstinence on uptake of reproductive health services. 2) To establish if students' attitude on being faithful to one partner influenced uptake of reproductive health services. 3) To determine if students attitude on condom use and influenced uptake of reproductive health services. 
Null hypothesis: The study hypothesised that; 1) there is no significant relationship between students' attitude towards abstinence and uptake of reproductive health services. 2) There is no significant relationship between students' attitude on being faithful to one partner and uptake of reproductive health services. 3) There is no significant relationship between students' attitude on condom use and uptake of reproductive health services.

Delimitations of the Study The study focused on university students who were residents within the KU main campus. In consideration of this, generalizations of the findings to other students in other universities must be done with caution.

Limitations of the study The study was confined only to undergraduate students in the regular mode of study programme thus locking out other students' indifferent levels of their studies and other modes of study.

\section{Theoretical framework}

This study was based on the Health Belief Model (HBM) by Rosenstock et al., 1988). According to Rosenstock et al., (1988) HBM is a cognitive model for understanding health risk behaviour including high risk sexual behaviour among various age groups making it suitable for this study. The HBM predicts whether individuals undertake preventive health behaviours and is contingent on five factors: (a) an individual's perception to susceptibility to an adverse health outcome; (b) an individual's perception of the level of severity of the adverse health outcome and related consequential outcomes; (c) an individual's perceptions of the benefits of given preventive behaviours in terms of helping them avoid the adverse health outcome; (d) an individual's perception of barriers to (or costs of) implementing given preventive behaviours. The fifth factor is the level of perceived self-efficacy which refers to the degree to which individuals believe that they are capable of implementing preventive actions (Rosenstock et al., 1988).

In addition, students' attitude was hypothesized to influence students' engagement in high risk sexual behaviours. It was envisaged that students' with a positive attitude to behaviours that promoted safe sexual practises. Such as the ABC strategy will not indulge in high risk sexual behaviour. On the other hand, the study hypothesized that students' who had a negative attitude to adoption of the ABC strategy in their lifestyle most probably engaged in HRSB. Thus putting them at risk of encountering adverse reproductive health issues. Hence, refrain from utilizing reproductive health services on campus. Students' attitude towards service provision was also assumed to influence uptake of reproductive health services

\section{Literature review}

\section{Students attitudes towards reproductive health services}

Students' attitudes towards ABC strategy: A study by Liku, et.al (2010) on students' attitude towards ABC strategy at University of Nairobi (UoN) revealed that students attitude towards ABC strategy towards HIV and AIDS and unintended pregnancy prevention was not entirely positive though knowledge on ABC was relatively high (over $70 \%)$.

A study by Kairu (2006) in Kenyatta university revealed students had a positive attitude towards ABC strategy on HIV prevention. More than half of the student population interviewed $(51 \%)$ had a positive attitude on abstinence, only $20 \%$ had a positive attitude to being faithful and only $17 \%$ had a positive attitude towards condom use. However their attitude on practicability of the ABC strategy abstinence was ranked number three, followed by being faithful to one partner and condom use as most effective. Therefore, this study sought to further explore if KU students attitude on ABC strategy influenced uptake of reproductive health services.

Health service providers' (HSP) attitudes have been identified as a major barrier that discourages young people from seeking or going back for reproductive health services (Godia, 2012; Obonyo, 2009). A study by Warenius 
et al., (2006) in Kenya and Zambia revealed that reproductive health services were underutilized by youths due to judgmental attitude of health providers and lack of competence coupled with lack of knowledge in youth friendly service provision. A study in Ethiopia on health workers attitude toward sexual and reproductive health services for unmarried youth revealed that some health workers were setting up penal rules and regulations against premarital sex thus restricting youths from visiting the RHS (Tilahun et al., 2010). Studies also indicate that HSP influence uptake of reproductive health services as most youth report that they are afraid of HSP because they ask personal and judgmental questions and sometimes give advice that is scary which discourages them from seeking services (Godia, 2012). Thus the study sought to examine student's attitude of the health service provider's friendliness and how it has influenced uptake of reproductive health services at Kenyatta University.

Assumptions of lack of anonymity and confidentiality have been seen as a hindrance to access and uptake of reproductive health services. A study by (Kiran et al., 2015) revealed that majority of student's participants (71\%) said the lack of confidential services was a significant barrier to their utilization of Sexual Reproductive Health (SRH) services. Similarly, 30\% believed available services were inadequate to meet their SRH needs hence did not utilize the service or sought for them elsewhere. Thus the study sought to examine KU student's attitude of the health service provider's friendliness and if confidentiality was maintained thus influencing their uptake of reproductive health services.

\section{Research Methodology}

Research design; This study used the survey research design which was cross-sectional because it was carried at one point in time. According Robson (2011), survey research seeks to obtain information that describes existing phenomena by asking individuals about their perceptions, attitudes, behaviour or values. The survey design is also convenient in collecting extensive data from a large scale of respondents within a short period of time (Mugenda and Mugenda, 2012). It yields reliable quantifiable data as it is collected at one point in time and conclusions can be inferred to the whole population (Kothari, 2004). For this study, it enabled the researcher to seek information from students on their attitudes how the attitudes influenced their uptake of reproductive health services. Independent variables: Students' attitude for ABC strategy was measured by a set of five items for each component scored on a five-point scale ranging from strongly disagrees to strongly agree. The attitude score was created by calculating the means of the items for each construct. Whereby, a high value score corresponded with a positive attitude and a low value score corresponded with a negative attitude.

Dependent variable The dependent variable for the study was students' uptake of RHS which was measured by student attesting to use of VCT, YFS, ACU, ICL, peer counseling, mentoring programmes and KU wellness Centre.

Target population The study targeted only registered undergraduate students' on regular mode of study residing in the main campus hostels during the first semester of academic year 2014/2015 from the month of September 2014 to December 2014.

Inclusion criteria The study only included registered undergraduate students for academic year 2014/2015 first semester residing within the main campus hostels from September 2014 to December 2014 as the main participants for the research. These students were more likely to access and utilize the services that are situated within the campus compared to nonresident students' who may decide to seek services outside the campus.

Exclusion criteria Registered undergraduate students for academic year 2014/2015 first semester who were not residents within the main campus hostels at the time of study were excluded from the study.

Sampling technique Sampling technique is part of the research plan that indicates how cases are to be selected for observation. In this study, a combination of purposive sampling, proportionate sampling and stratified and 
simple random sampling were used. Kenyatta University main campus student residential area is divided into three zones which were all included in the study. In order to ensure a representative sample, proportionate random sampling was done from the three residential zones. Stratified random sampling was used to select four hostels from each zone whereby two were male hostels and two female hostels to ensure gender representation from where respondents were to be selected. Simple random sampling was used to get to the respondent.

Sample size The population for students residing in main campus was approximately 10,033 students The sample size for the study was determined using fisher et al., (1995) formula for a population of above 10,000.

$$
\frac{n=\mathrm{Z}^{2} p(1-p)}{d^{2}}
$$

Where;

$n$ - Sample size

Z- Statistic for a level of confidence (95\% level of confidence, $Z$ value is 1.962 )

$p$ - Expected proportion in the target population. (Assuming 50\%, $\mathrm{p}=0.05$ )

$d$ - Precision level of statistical significance $(7 \%, \mathrm{~d}=0.07)$

$$
\begin{gathered}
n=(1.962)^{2} \times 0.5(1-0.5) \\
(0.07)^{2} \\
n=200
\end{gathered}
$$

Therefore, from this equation a total of two hundred students (200) were selected as respondents for this study.

Data collection tool and procedure : Data from the student participants was collected by use of a selfadministered questionnaire since it guaranteed anonymity and confidentiality. Kothari (2004) stipulates that use of the questionnaire is one of the major ways to elicit self-reports on people's opinions, attitudes, beliefs and values. The questionnaire contained closed-ended questions to provide specific responses and open ended items for in depth information. Open ended questions permit a greater depth of response and give an insight into the respondents' feelings, backgrounds, hidden motives and intentions (Mugenda and Mugenda, 2012).

For the administration of student questionnaire, the researcher together with the help of two trained research assistants visited the selected hostels in the evening during weekdays from $5 \mathrm{pm}$ to $7 \mathrm{pm}$ after classes. Students' approached in the selected hostel, were first engaged by creating a rapport between the researcher and student explaining the purpose of the study. Probing of the student was done to ascertain they were the ones allocated the given room. Students' consent to participate in the study was sought who upon consenting would sign the consent form and a questionnaire was then handed over for them to fill. Students' were also informed the researcher preferred to wait for them to fill up the questionnaire.

Pre-testing Before commencing the study, pre-testing of the study instruments was conducted. The aim of pretesting was to assist in determining accuracy, clarity and suitability of the research instruments and to check their validity and reliability (Mugenda and Mugenda, 2012). The pre-testing study was conducted at the school of business and involved a total of fifteen students. The fifteen students were self-sponsored students who were not residents in the main campus hostel hence could not be duplicated in the main study. Two staff members employed to offer services at the university programmes were also involved in the pre-testing. Adjustments were made in order to make to make the research instruments more appropriate before the actual field work begun. The responses derived from the pretest were used by the researcher to refine the questionnaire by rephrasing and editing thus ensuring that the questions conveyed the same meaning to all respondents. The pretest enabled the researcher to test the appropriateness of the study tool by ensuring that items tested what they were intended to (validity) and that they consistently measured the variables in the study (reliability). It also helped to estimate the length of time for the administration of instruments. 
Validity of instruments Validity refers to the extent to which an instrument measures what it is intended to measure based on objectives (Kothari, 2004).To enhance validity of the research instruments, peer review was done where the study proposal was presented twice at the department. Consistent consultations were done by the researcher together with supervisors and other expatriates who were knowledgeable in the reproductive health field of study. This helped in establishing ambiguous questions and missing gaps in the questionnaire, and corrections were made on research items that were not clear before being used in the actual study.

Reliability of instruments Reliability of measurement is the degree to which a particular measuring procedure gives similar results over a number of repeated trials thus, pre-testing is a good way to check for reliability of the data collection instruments (Kothari, 2004).Reliability test was conducted for the likert scale items using Statistical Package for Social Sciences (SPSS) where internal consistencies were analysed using Cronbachs coefficient alpha. The results of Cronbachs Coefficient Alpha yielded a value of 0.78 which was acceptable.

\section{Logistical and Ethical considerations}

Prior to conducting the study, Permission from relevant authorities' in relation to this study was sought. Approval from the graduate school was sought permitting the researcher to proceed in the area of study. Permission from Kenyatta University Management was mandatory since the study was based within the university. An acceptance letter was issued that facilitated the researcher to conduct the study within the university. Ethical clearance was also sought from Kenyatta University Ethics Review Committee the research body in the university mandated to review proposals. A research permit to conduct the study was obtained from the National Commission for Science, Technology and Innovation (NACOSTI) which is the national research coordinating body in Kenya. Voluntary participation and consent of respondents was sought before commencement of study and respondents were requested to sign the consent form when they agreed. The respondents were assured of confidentiality and also informed that they could withdraw from the study, when they so wished without any consequences.

Data analysis This study generated both qualitative and quantitative data. Quantitative data collected was analysed using the Statistical Package for Social Sciences (SPSS). Descriptive statistics of means, frequencies and percentages were used to describe and summarize data. Inferential statistics used included chi-square to test relationship among variables. Data presentation was done through tables.

The qualitative data obtained from the open ended questions in the students' questionnaire was manually explored, to check for emerging themes. They were then clustered in a patterned order so as to identify variables that depicted general concepts that occurred repeatedly. Information generated was also statistically analyzed so as to elaborate on factors influencing students' uptake of reproductive health services. Chi-square test of significance at a significance level of $\mathrm{P}<0.05$ was used to establish the relationship between the dependent and independent variables. The chi-square test of was preferred since both the dependent and independent variables used in the study were categorical.

The targeted sample size for this study was 200 students. However, a total of 178 respondents participating in the study were used for analysis indicating a response rate of 89.0\%. According to Timothy and Wislar (2012), a response rate of $85 \%$ and above is considered to be good. The non-response rate by participants was contributed to the fact that $6 \%$ of the questionnaires were not dully filled thus could not be analyzed, and $5 \%$ of the students did not submit back their questionnaires. 


\section{Research findings}

\section{Students attitude of ABC strategy as a safe sex practise}

The researcher sought to obtain students' attitude on selected safe sex practise that could be attributed to students' uptake of reproductive health services. This was guided by the abstinence, being faithful to one partner and condom use $(\mathrm{ABC})$ behavioural preventive strategy. $\mathrm{ABC}$ strategy was regarded as protective factor for behaviour change thus resulting to a positive health outcome in curbing high risk sexual behaviour.

Table 1: Students attitude towards ABC strategy

\begin{tabular}{lllllll}
\hline ABC strategy & \multicolumn{2}{c}{ Positive } & \multicolumn{2}{c}{ Negative } & \multicolumn{3}{c}{ Total } \\
\cline { 2 - 7 } & $\mathrm{F}(\mathrm{n})$ & $\%$ & $\mathrm{f}(\mathrm{n})$ & $\%$ & $\mathrm{~F}(\mathrm{~N})$ & 100 \\
\hline Abstinence & 71 & 39.9 & 107 & 60.1 & 178 & 100 \\
\hline Being faithful to one partner & 128 & 71.9 & 50 & 28.1 & 178 & 100 \\
\hline Condom use & 102 & 57.3 & 76 & 42.9 & 178 & \multirow{2}{*}{100} \\
\hline
\end{tabular}

Findings from table 1 reveal that more than half of the students $60.1 \%$ had a negative attitude on abstaining this indicates the desire to indulge in premarital sex that can lead to high risk sexual behaviours such as early sexual debut among students. Thus students engaging in premarital sex may fear utilizing reproductive health services with the attitude that the health service providers will judge them for engaging in premarital sex. Whereas only $39.9 \%$ of the students who had a positive attitude in abstaining till marriage.

Students had a positive attitude to being faithful to one partner with nearly three quarters (71.9\%) of the students agreeing it's essential to remain faithful to one partner. With only $28.1 \%$ of the students having a negative attitude towards being faithful to one partner. Thus this could result to students utilizing reproductive health services to seek services such as family planning and counseling seeing on how to have healthy relationships.

Students also had a positive attitude with more than half of the students (57.3\%) feeling that it was important for one to use condom use when engaging in sex. Whereas $42.9 \%$ of the students had a negative attitude towards condom use. Negative attitude towards condom use could result to increased uptake of RHS as individuals may seek help to avert consequences associated with lack of condom use for example post exposure prophylaxis, getting emergency pills at the YFS as well as VCT services to check if they have contracted the virus.

\section{Student's Attitude on Abstinence and Uptake of Reproductive Health Services}

The study sought to establish if students' attitude in abstinence had any influence on their uptake of reproductive health services. Results, of these findings are presented in table 4.24.

Table 2 Abstinence and Uptake of RHS

\begin{tabular}{llll}
\hline Abstinence & Utilized RHS & Not utilized RHS & Total \\
\hline Positive & 14 & 57 & 71 \\
& $19.70 \%$ & $80.30 \%$ & $100 \%$ \\
\hline Negative & 65 & 42 & 107 \\
& $60.70 \%$ & 39.3 & $100 \%$ \\
\hline Total & 79 & 99 & 178 \\
& $44.40 \%$ & $55.60 \%$ & $100 \%$ \\
\hline
\end{tabular}

$\chi^{2}=12.432 ; C=0.256 ; \mathrm{df}=4 ; \mathrm{p}=0.014$ 
Results presented in table 4.24 above reveal that only $19.7 \%$ with a positive attitude had utilized reproductive health services whereas more than three quarter $(80.3 \%)$ who had a positive attitude did not utilize reproductive health service. This could mean that students with a positive attitude towards abstinence perceived they were safe from ill sexual health thus did not find the need to utilize reproductive health services.

Findings indicate that more than half of the students $(60.7 \%)$ with a negative attitude towards abstaining utilized reproductive health services. This could be an indication that students perceived themselves at risk and susceptible to illness due to their engagement in sexual activity thus sought RHS for protective measures or treatment Whereas, only $39.3 \%$ with a negative attitude had not utilize reproductive health services.

Chi-square results $\left(\chi^{2}=12.432 ; C=0.256 ; \mathrm{df}=4 ; \mathrm{p}=0.014\right)$ show there was a significant relationship between students attitude on abstinence and uptake of reproductive health services at a significance level of 0.05.Therefore, the null hypothesis that there was no significant relationship between students' attitude and uptake of reproductive health services was rejected for abstinence.

\section{Being Faithful to One Partner and Uptake of Reproductive Health Services}

Being faithful to one partner was an important variable in this study as this would probably reduce students' engagement in multiple sexual partners. Moreover, studies have shown that individuals in stable relationships have high self-efficacy on negotiating for condom use and contraceptives and are most likely to engage in safe sexual practises (Schimdt, 2015). Hence, the study sought to establish if students' attitude in being faithful to one partner had influence on uptake of reproductive health services.

Table 3 Being Faithful to One Partner and Uptake of RHS

\begin{tabular}{llll}
\hline Being faithful to one partner & utilized RHS & not utilized RHS & Total \\
\hline Positive & 56 & 72 & 128 \\
& $43.70 \%$ & $56.30 \%$ & $100 \%$ \\
\hline Negative & 23 & 27 & 50 \\
& $46 \%$ & $54 \%$ & $100 \%$ \\
\hline Total & 79 & 99 & 178 \\
& $44.40 \%$ & $55.60 \%$ & $100 \%$ \\
\hline
\end{tabular}

$\chi^{2}=1.309 ; \mathrm{C}=0.085 ; \mathrm{df}=4 ; \mathrm{p}=0.860$

Results presented in Table 3 show that $43.7 \%$ students with a positive attitude on being faithful to one partner had utilized reproductive health services whereas more than half of the students $(56.3 \%)$ with a positive attitude did not utilize reproductive health services. Fining continue to reveal that nearly half of the students $(46 \%)$ with a negative attitude towards being faithful to one partner utilized reproductive health services thus they perceived to be at risk of sexual health illness maybe due to their engagement in HRSB such as having multiple sexual partners. Whereas more than half $(54 \%)$ with a negative attitude did not utilize reproductive health services

The Chi-square results $\left(\chi^{2}=1.309 ; \mathrm{C}=0.085 ; \mathrm{df}=4 ; \mathrm{p}=0.860\right)$ reveal there was no significant relationship between students attitude on being faithful to one partner and uptake of reproductive health services at a significance level of 0.05 . Thus, the null hypothesis that there was no significant relationship on students' attitude and uptake of reproductive health services was retained for being faithful to one partner. 


\section{Students' Attitude on Condom Use and Uptake of Reproductive Health Services}

Students attitude on condom use was assessed and its influence to uptake of reproductive health services. Results of this study regarding students' attitude on condom use and uptake are presented in Table 3.

Table 3: Condom use and Uptake of Reproductive Health Services

\begin{tabular}{llll}
\hline Condom use & Utilized RHS & Not utilized RHS & Total \\
\hline Positive & 59 & 43 & 102 \\
& $57.80 \%$ & $42.20 \%$ & $100 \%$ \\
\hline Negative & 20 & 56 & 76 \\
& $26.30 \%$ & $73.70 \%$ & $100 \%$ \\
\hline Total & 79 & 99 & 178 \\
& $44.40 \%$ & $55.60 \%$ & $100 \%$ \\
\hline
\end{tabular}

$\chi^{2}=14.926 ; \mathrm{C}=0.278 ; \mathrm{df}=4 ; \mathrm{p}=0.005$

Findings presented in Table 3 indicate that there was a significant relationship between students' attitude on condom use and uptake of reproductive health service. Results show that more than half of the students (57.8) with a positive attitude towards condom use had and $42.2 \%$ of the students with a positive attitude to condom use did not utilize reproductive health services. Whereas, nearly a quarter of the students (26.3\%) with a negative attitude towards condom use had utilized RHS and nearly three quarter of the students (73.7\%) with a negative attitude towards condom use had not utilized reproductive health services

This finding could be an indication that students who had a positive attitude to safe sexual practises engaged in positive sexual behavioural practises such as condom use and utilizing of reproductive health services. On the other hand, those with negative attitude towards safe sexual practises engaged in negative sexual behavioural practises like inconsistent/lack of condom use, not utilizing reproductive health services and hence could be at high risk of suffering from adverse consequences of engaging in high risk sexual behaviour.

The chi-square results $\left(\chi^{2}=14.926 ; \mathrm{C}=0.278 ; \mathrm{df}=4 ; \mathrm{p}=0.005\right)$ revealed there was a significant relationship between students attitude on condom use and uptake of reproductive health services at a significance level of 0.05. Thus, the null hypothesis stating that there is no significant relationship between students' attitude and uptake of reproductive health services was rejected with regard to condom use.

\section{Discussion of findings}

\section{Students attitude influencing uptake of reproductive health services}

The study established that students' attitude to the ABC strategy for protective sexual behaviour influenced uptake of reproductive health services. Students' attitude on condom use had a significant relationship in utilization of reproductive health services. This could be attributed to the fact that most of the students with a positive attitude utilized reproductive health services in order to get more information on condom use as well as get more condoms that are distributed at the RH programmes. Those with a negative attitude towards abstaining till marriage majority had utilized reproductive health services an indicator that students' were engaging in sexual relations when not married and could also mean student engagement in HRSB.

An association between being faithful to one partner and seeking of reproductive health services was discovered with majority of those who strongly believed in being faithful to one partner having sought services from the various programmes. These findings are in agreement with Kairu (2006) and Liku et al., (2010) studies on students' attitude to ABC strategy have called for the need of RH programmes to redouble their efforts in 
strengthening the ABC strategy among university students in order to positively influence students' sexual behaviour.

\section{Conclusion}

The study established that more than three quarter (71.9\%) of the students had a positive towards being faithful to one partner. And more than half $(57.3 \%)$ had a positive attitude to condom use. Nearly half $(41.6 \%)$ of the respondents had a positive attitude that reproductive health service providers were friendly and maintained confidentiality. However, majority of the students' more than half $(60.1 \%)$ had a negative attitude to abstaining.

Uptake of reproductive health services was significantly related to students attitude on abstinence $(p=0.014)$, condom use $(\mathrm{p}=0.005)$, confidentiality is maintained $(\mathrm{P}=0.001)$ and service providers were friendly $(\mathrm{P}=0.000)$.Hence, hypothesis there was no significant relationship between students' attitude and uptake of reproductive health services was rejected for this study. Based on the findings, students' attitude was found to greatly influence uptake of RHS.

\section{Recommendations}

In view of the findings that emerged from this study, the following recommendations are made with regard to practise: Programmes need to adopt strategies that strengthen ABC strategy so as to influence students' attitude to adopt safe sex practises. A comparative study could be carried out between students residing off campus and those residing on campus to establish whether there are differences in their uptake of reproductive health services in the University.

\section{References}

Adam, M. B., and Mutungi, M. 2007. Sexual Risk Behavior among Kenyan University Students. Journal of the Arizona-Nevada Academy of Science Vol. 39(2) 91-98,

Evidence to Action. (2016). Kenyatta University Youth Friendly Services Assessment Report . (Accessed on $10^{\text {th }}$ May 2016)

Godia,P.M. 2012.Sexual Reproductive Health Service Provision to Young People in Kenya; what is the best model? Doctoral thesis, University of Liverpool.(unpublished)

Heeren G.A., Jemmott III B., Zolani N., Mandeya A., Tyler J.C. 2012. A Randomized Controlled Pilot Study of an HIV Risk-Reduction Intervention for Sub-Saharan African University Students. Accessed online: 12 August 2013.

Johnson,A. 2011. Multicontextual influences on high risk behaviors among college students. University of La Verne, 2011, 145 pages; AAT 3455614

Johnson, B.T., Scott-Sheldon, L.A., Smoak, N.D., Lacroix, J.M., Anderson, J.R., \& Carey, M.P. 2009 . Behavioral interventions for African Americans to reduce sexual risk of HIV: A meta-analysis of randomized controlled trials. Journal of Acquired Immune Deficiency Syndrome, (51), 492-501.

Kairu, G.M. 2006.Students attitudes to ABC as a strategy for HIV/AIDS prevention within Kenyatta University, Nairobi County, Kenya. Masters thesis Kenyatta University.

Kamau, A. W. 2006. Factors influencing access and utilization of preventive reproductive health services by adolescents in Kenya: a case study of Murang'a District. Bielefeld: University.urn:nbn:de:hbz:361-9317.

Kenya National Bureau of Statistics (KNBS) and ICF Macro.2010 . Kenya Demographic and Health Survey 2008-09. Calverton, Maryland: KNBS and ICF Macro.

Kimiywe, J., Ogol, C.K., Waudo, J., Mwanzo, I. and Orida G. 2008. HIV\&AIDS Baseline Sero-behavioural Study in Six .Addressing mobility, vulnerability and gaps in integrated response to HIV \& AIDS in the lake victoria basin.

Kiran, B., Fariha H., Rajendra K. B.C., Sophia N., Asiful H.C., Rajshree T., and Ismat B. 2015."Perceived Sexual and Reproductive Health Needs and Service Utilization among Higher Secondary School Students in 
Urban Nepal."American Journal of Public Health Research, vol. (3), no. 2 2015: 36-45. doi: 10.12691/ajphr-3$2-1$

Kirby,D. 2011. Sex Education: Access and Impact on sexual behavior of young people. United Nations Expert Group meeting on Adolescents, Youth and Development Population Division Department of Economic and Social Affairs United Nations Secretariat New York 21-22 July 2011.

Kothari, C.R. 2004. Research Methodology; Methods and Techniques. (New Delhi: New Age International).

Liku,J., Kioko,A. and Katz, K. 2010 Testing the A-B-C Approach for Infection Prevention and Averting Unintended Pregnancies among Youth in Institutions of Higher Learning. Assessment report accessed on $15^{\text {th }}$ September 2015.

Liverpool J, McGhee M, Lollis C, Beckford M, Levine D 2002 Knowledge, attitudes, and behavior of homeless African-American adolescents: implications for HIV/AIDS prevention. $\mathrm{J}$ Natl Med Assoc 94(4):257-263

Majelantle R.G., Keetile, M., Bainame K., and Nkawana, P. 2014 Knowledge, Opinions and attitudes towards HIV and AIDS among Youth in Botswana. J Glob Econ 2: 108. doi:10.4172/economics.1000108

Manago, A. M., Ward, L. M. and Aldana, A. 2015. The Sexual Experience of Latino Young Adults in College and Their Perceptions of Values About Sex Communicated by Their Parents and Friends. Emerging Adulthood 2015, Vol.3(1) 14-23 DOI: 10.1177/2167696814536165

Manoti, L.M. 2015 Factors Influencing Access To Sexual Reproductive Health Services. ACase Of The University Of Nairobi Main Campus Undergraduate Students Institute Of Anthropology And African Studies Unit In Kenya. Master's Thesis University of $\quad$ Nairobi (Accessed on 21st May 2016)

Miller, A.N., Mutungi, M., Facchini, E., Barasa, B., Ondieki, W., Warria, C. 2008 . An outcome assessment of an ABC-based HIV peer education intervention among Kenyan university students. Journal Health Community 13(4):345-56.

Ministry of Health 2006. 'Health services availability and utilization' Government Of Kenya, MoH available at http://www.health.go.ke/ [accessed 2015, January 03].

Moronkola, O. \& Idris, M. 2013 .Sexual health knowledge determinants of sexual behaviour and use of contraceptives among female secondary school students in Ibadan Nigeria. Nigerian School Health Journal, (12)1-2, 27-35.

Mugenda,O.M. and Mugenda, A.G. 2012. Research Methods Dictionary. (Nairobi: ARTS Press) .

Mugenda,O.M. and Mugenda,A.G.1999. Research method: quantitative and qualitative approaches. (Nairobi: ARTS Press).

Mwangi, R.,Ngure, K. and Thiga M.2012. Factors Influencing the Utilization of VCT Services among University Students in Kenya Daystar University Centre for Research, Publications and Consultancy Working Paper Series Working Paper Series Number DU/2012/005. Accessed on $14^{\text {th }}$ April 2015

Rosenstock, I. M., Strecher, V. J., and Becker, M. H. 1988.Social learning theory and the health belief model.Health Education \& Behavior (15): 175-183.

Schmidt, S.C. 2015 School-Based Sexuality Education, Gender, and Relationship Self Efficacy: A ModeratedMediation Analysis of Sexual Behavior in First Year College Students

Sinead N. Y., Maya A. C., Lyde M.S., Cannady, J. 2013. The Paradox of Risk: Historically Black College / University Students and Sexual Health. Journal of American College Health, Vol. (61), No. 5.Accessed on $14^{\text {th }}$ April 2015

Smith S. J. 2015. Risky Sexual Behavior Among Young Adult Latinas: Are Acculturation and Religiosity Protective? Journal of Sex Research, 52(1), 43-54

Timothy P.J and Wislar J. S. (2012).Response Rates and Non- Response Errors in Surveys. JAMA 2012; 307 (17): 1805-1806. Doi: 10.100/2012 3552.

Walsh, W. A., Banyard, V. L., Moynihan, M. M., Ward, S., \& Cohn, E. S. 2010. Disclosure and service use on a college campus after an unwanted sexual experience. Journal of Trauma \& Dissociation, (11), 134151.Accessed on $14^{\text {th }} \quad$ April 2015

WHO. 2009a. "Global Health Risks: Mortality and Burden of Disease Attributable to Selected MajorRisks.”http://www.who. int/healthinfo/global_burden_ disease/Global Health Risks_ report_ full.pdf?ua $1 / 41$ Accessed on $14^{\text {th }}$ April 2015 
Mary Wanjau et al / ABC Strategy: How University Students Perception.....

WHO. 2009b. A Snapshot of the Health of Young People in Europe. Copenhagen: WHO EuropeanOffice.http://ec.europa.eu/health/mental health/eu_compass/reports studies/snapshot young. Accessed on $14^{\text {th }}$ April 2015 